\title{
44553 - LOW-DOSE KETAMINE DOES NOT REDUCE MORPHINE USE AFTER SPINE SURGERY
}

\author{
Ban Tsui, University of Alberta, Edmonton, AB, Canada; \\ Alese Wagner, University of Alberta; \\ Stephan Malherbe, University of Alberta; \\ $J$ Mahood, University of Alberta; \\ M Moreau, University of Alberta;
}

INTRODUCTION: Adequate post-operative analgesia for spinal instrumentation and correction of scoliosis is challenging due to the severe pain experienced and a limited number of analgesic options (e.g. opioids and acetaminophen). (1) Non-steroidal anti-inflammatory drugs inhibit osteogenesis (2) and epidurals are controversial. Balanced analgesia using adjuvant low-dose ketamine may reduce opioid consumption and adverse effects, by reducing acute opioid tolerance and rebound hyperalgesia. (3) This study evaluated whether using a low-dose adjuvant ketamine infusion could reduce postoperative pain and opioid consumption in this patient population.

METHODS: Pediatric patients undergoing elective posterior spinal instrumentation and able to receive patient-controlled analgesia (PCA) were included in this double-blind, randomized (1:1) study, after REB approval, written informed assent and parental consent. One group received a continuous low-dose intravenous ketamine infusion at $0.2 \mathrm{mg} / \mathrm{kg} / \mathrm{hr}$; the other received an infusion of saline at the same rate. Both infusions were started in the operating theatre prior to incision and all patients received the same anesthetic plan. Each patient received a morphine 0.08 $\mathrm{mg} / \mathrm{kg}$ bolus followed by an infusion of $0.04 \mathrm{mg} / \mathrm{kg} / \mathrm{hour}$ until the end of the procedure. The attending anesthesiologist was blinded to the infusion identity but was able to administer fentanyl boluses at $0.5-1 \& \# 956 ; \mathrm{g} / \mathrm{kg}$ if indicated by observed hemodynamic responses. In the post-anesthetic recovery room the patients received PCA morphine $0.02 \mathrm{mg} / \mathrm{kg}$ (or hydromorphone $0.004 \mathrm{mg} / \mathrm{kg}$ ) set at a lockout of 8 minutes. Verbal pain (0-10) and sedation scores (0-3), PCA totals and additional medication doses were recorded at 30 and 60 min and 4, 8,12 , and 48 hrs by blinded nurses. Pain and functional mobility (7-point scale) scores were assessed during physiotherapy starting on POD \# 1. Results were reported by frequency or mean \pm SD and groups were compared using Student's T-test at $p=0.05$ significance.

RESULTS: Ten patients (5 per group) were enrolled. The ketamine group used more PCA morphine at $4 \mathrm{hrs}[0.39 \pm 0.08$ (ketamine) vs $0.14 \pm 0.11$ (saline) $\mathrm{mg} / \mathrm{kg}, \mathrm{p}=0.004$ ). 
Figure. Postoperative PCA morphine consumption

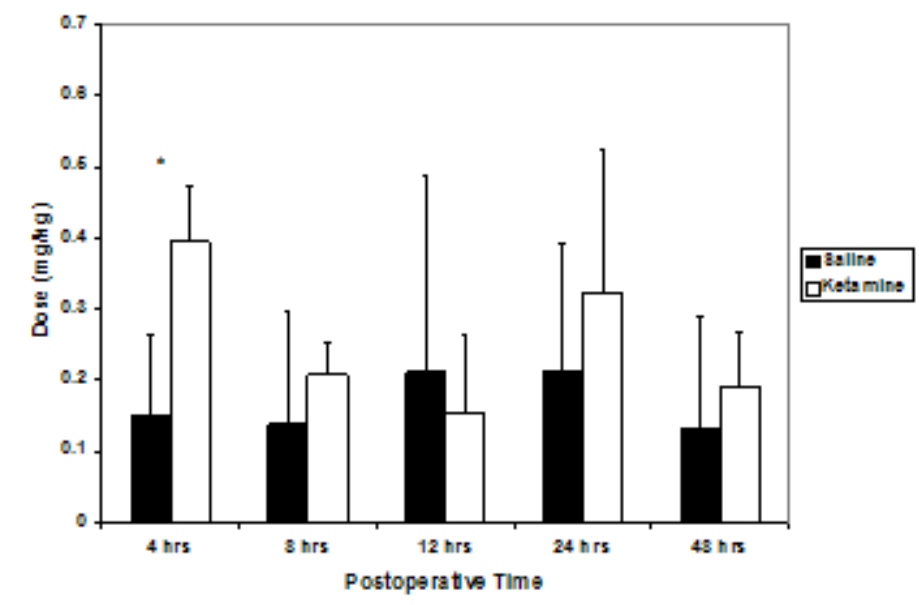

There was slightly higher functional mobility during physiotherapy in the ketamine group (Day 1: $2.54 \pm 1.02$ vs $2.2 \pm 0.94$; Day 2: $3.76 \pm 1.14$ vs $3.25 \pm 0.75$ ) but there was no significant difference in this or any other parameter. No patient in the ketamine group experienced psychomimetic effects.

DISCUSSION: This study suggests that adding low-dose intravenous ketamine $0.2 \mathrm{mg} / \mathrm{kg} / \mathrm{hr}$ to PCA morphine may not reduce morphine consumption in children undergoing posterior instrumentation and scoliosis correction. Ketamine may increase ease with early mobility as found in other work. (4)

REFERENCES: 1. Int Ortho 1996; 20: 295-299. 2. Spine 1998; 23: 834-838. 3. Pain 2001; 92: 373-380. 4. Anaesth Intensive Care 1996; 24: 32-36. 